UDC 614.253

Susanna DAVTYAN,

Tatevik PIRUMYAN

\title{
TOLERANCE AS A CONSTRUCTIVE MECHANISM OF DIALOGUE IN THE FIELD OF HEALTHCARE
}

\begin{abstract}
Modern bioethical issues (doctor-patient relationship) should be based on a tolerant attitude towards patient. Tolerance is an important value in Ethics, medical Ethics and Bioethics. As a moral norm, tolerance is a virtue. It is a rational human response, social value, which ensures the rights, freedom and security of human beings. Tolerance is a social ideal originating in society.
\end{abstract}

Keywords: tolerance, trust, respect, dialogue, doctor-patient relationship, informed consent.

In the modern globalized world, the problem of tolerance as a mechanism for constructing trust and dialogue has a great importance. Nowadays tolerance is more crucial than ever before. The leading role of tolerance is obvious in almost all areas of the contemporary world: moral, medical, political, economic, cultural, social, etc. As a social-cultural norm tolerance is a capacity to endure different opinions, thinking of views, ideas and lifestyle. It is the ability to respect and accept cultural diversity, different ethnic and social groups and religions. In order to understand what tolerance is and its role in the modern bioethical issues, particularly in the doctorpatient relationship, first we should take into consideration the origin, theoretical foundations and historical stages of development of tolerance.

Tolerance is a complicated and multifaceted social-cultural phenomenon. "At first glance the idea of tolerance seems to be very simple but in fact it isn `t like this at all. Toler- ance is closely related to the fundamental philosophical issues focusing on the discovery of human nature, understanding human identity, the boundaries of human knowledge and capabilities" (Lektorskiy, 1997, p. 46). In order to determine the concept of tolerance first we should mention that it is a cultural quality of each citizen, regardless of age, gender religious, ethnic and racial background. According to the linguistic analysis, tolerance (Latin «tolerantia») is defined:

1. as an ability of organism, power of enduring or resisting the negative effects and action of a drug, poison, etc.

2. as a patient and tolerant attitude towards something or somebody. Tolerance has different meanings in different languages depending on each nation's cultural, historical and national features.

According to the Declaration of Principles on Tolerance adopted by the General Conference of UNESCO at its twenty-eighth session in Paris, on 16 November 1995. 
1. Tolerance is respect, acceptance and appreciation of the rich diversity of our world's cultures, our forms of expression and ways of being human. It is fostered by knowledge, openness, communication, and freedom of thought, conscience and belief. Tolerance is harmony in difference. It is not only a moral duty; it is also a political and legal requirement. Tolerance, the virtue that makes peace possible, contributes to the replacement of the culture of war by a culture of peace.

2. Tolerance is, above all, an active attitude prompted by the recognition of the universal human rights and fundamental freedoms of others.

3. Tolerance is the responsibility that upholds human rights, pluralism (including cultural pluralism), democracy and the rule of law. It involves the rejection of dogmatism and absolutism and affirms the standards set out in international human rights instruments.

4. Consistent with respect for human rights, the practice of tolerance does not mean toleration of social injustice or the abandonment or weakening of one's convictions. It means accepting the fact that human beings, naturally diverse in their appearance, situation, speech, behavior and values, have the right to live in peace and to be as they are. It also means that one's views are not to be imposed on others ${ }^{1}$.

As we see, according to the UNESCO's Declaration of Tolerance, the main character-

1 Declaration of Principles on Tolerance adopted by the General Conference of UNESCO at its twenty-eighth session in Paris, on 16 November 1995, p. 9-10. istics of tolerance are variety and differences. The aim of Declaration of principles on Tolerance is preserve the world from the religious, political and cultural wars, which are inevitable in the modern globalized world. Only the acceptance of the principle of tolerance is able to face the various challenges of the $21^{\text {st }}$ century, which is growing and becoming uncontrollable.

As a moral norm, tolerance is a virtue. It is a rational human response, which depends on the level of individual's knowledge, personal experience and skills. Tolerance does not mean patient attitude towards social injustices. Being tolerant, does not mean to give up own beliefs and adopt other ideologies. Tolerance is a social value, which insures human rights, freedom and security. The meaning of tolerance has changed from religion tolerance into moral tolerance and is now perceived as a moral principle and the universal value of the modern world.

Tolerance is a significant value in ethics, bioethics and medical ethics. The contemporary bioethical dilemmas and problems (doctor-patient relationship, human cloning and genetic engineering, organ transplantation, abortion of human embryos, euthanasia, medical secrets, patient's rights and doctor's duties, palliative care, etc.) should be based on tolerant attitude towards all human beings. In the doctor-patient relationship, it is important that the doctor is tolerant and respectful towards patient, because the treatment process and efficiency directly depends on the nature of the relationship between doctor and patient. "All doctors are well aware that recovery does not often depend on the nature of the intervention and/or effectiveness of drug therapy but rather on the fact if the patient believes in 
the therapy, or whether he/she wants to get better or prefers the role of patient, if he/she likes or dislikes the doctor and so forth. The influence of the socio-psychological situation of the individual patient on the effectiveness of treatment is considered by physicians, but it does not arouse any real their professional interest. Therefore, the concept of personalized medicine is not complete and scientifically credible until specialists in humanities, first of all, in bioethics get involved in its development" (Sedova \& Basov, 2015, p. 21). First of all the doctor must take into account the patient's individual experiences and characteristics, because for the patient it is more important his/her own subjective disturbances and disease.

The main principle of doctor-patient relationship is tolerance towards patient's freedom of choice, rights, informed consent and medical secret. "Respect for patient autonomy is the basis of informed consent. For patients to be autonomous and provide informed consent, the treating physician or psychiatrist must provide adequate information to the patient about their illness and treatment options that are available" (Avinas, 2015, p. 51). In the case of informed consent, the doctor's ability of decision-making is vital. The doctor must know in which way to inform the information about patient disease. All patients, without any restriction, have fundamental rights to obtain relevant information about their disease and its further developments, accept or reject the treatment recommended by a doctor. The clear derivation of the constitutional right of the individual to decide which treatment to undergo is evidenced by its ability to represent a synthesis of two fundamental human rights: to the definition of this space of freedom for the individual it competes the right to self-determination as well as the right to health, because if it is true that every individual has the right to be cared for, he has also the right to receive adequate information on the nature in the course of treatment which may be submitted, as well as possible alternative therapies (Lorenzo, 2013, p. 35). Therefore physician must inform the patient about his/her health situation and disease, the treatment process, methods and possible risks. The doctor should be patient and tolerant. He/she must respect any choice of the patient, conscientiously fulfill patient's decision and wish.

According to the Lisbon Declaration on Patient Rights which adopted by the $34^{\text {th }}$ World Medical Assembly (1981) patient has right to medical care, right to freedom of choice, right to make his/her own decision without any restriction. This Declaration claims that the patient has the right to accept or refuse to accept medical treatment after getting information. According to this claim, the doctor must inform the patient about the purposes of medical tests ordered, about the results of diagnostic tests and treatment procedures as well as possible risks of treatment. This declaration gives rights to patients and restrict doctors' absolute autonomy (Davtyan, 2013, p. 74). Therefore the realization of the right treatment is largely depend on the doctor's professional skills, knowledge, experience, intellect and tolerant attitude. Before making a final decision, doctor need to stop and think more carefully, however, when she/he makes decisions in circumstances that are more difficult. The doctor must take into account all possible consequences either positive or negative.

The doctor's dilemma is: "To tell the 
truth to the patient or not?" During 2002-2008 years Yerevan State Medical University after M. Heratsi, department of social sciences with Institute of Philosophy, Sociology and Law of National Academy of Sciences of Republic of Armenia conducted sociological investigations. $\mathrm{PhD}$ students point out the fact that the people in prosperous developed countries are expected to undergo free of charge preventive examination (screening), several times a year. For example, in 2015 total health expenditure per capita in USA is more than 8000 USD, in Canada is 4429 USD, in France is 4124 USD, in Germany is 5002 USD, in Italy is 3126 USD, in Israel is 2428 USD, in Japan is 3768 USD, in Russian Federation is 957 USD and in Republic of Armenia is only $159 \mathrm{USD}^{2}$. If something suspicious is revealed, the patient calmly, and without any stress, accepts the information and starts the treatment, being quite sure that the illness is completely curable at that stage.

What is the situation like in Republic of Armenia? In country which, from a developed one has turned into a developing country it is almost impossible to get such a free annual examination; it can be available in very rare cases, which can be classified as being extremely critical. Patients are generally informed about their illness when they reach a terminal condition. In this case telling the patient about his/her incurable illness means warning him/her that death is close and his/her days are counted.

Unfortunately, the principles of a healthy mode of life is not very developed in Armenia. The role of mass media, family and

\footnotetext{
2 Total health expenditure per capita https://en.wikipedia.org/wiki/List_of_countries _by_total_health_expenditure_per_capita.
}

school is poor; they do not provide the population with decent and appropriate knowledge. No work is done in this direction in order to develop a culture of a healthy way of life, sport and food regime for people of different ages.

Yerevan is flooded with internet clubs. Every day new e-net clubs are being opened; they co-exist, side by side, on the same street; the main problem is that they offer young people a virtual life instead of a real one. In these clubs, filled with cigarette smoke, you can see young people just sitting, pushing the buttons and feeling as if they are the fastest runners, the best fighters and shooters, and the winners, etc.

Unfortunately, in real life a complex of inferiority arises, because it turns out that they are not only very far from being champion, but also they can't even shoot, fight, build or win at all. For a young man who is weakwilled the simplest way is to return to virtual life and get his immediate satisfaction there.

This problem calls for an urgent intervention by the government in order to provide an applicable solution. If the government will not take any measures and will pursue its policy to focus on profits, the situation can deteriorate, and we may run the risk of losing a considerable number of our younger generation. We should seed taste and striving endeavor for a healthy mode of life.

At the $\mathrm{PhD}$ students have pointed out, getting a medical service is, for the majority of the population, an expensive "pleasure". Nevertheless, it is worth mentioning that even in cases when people can afford to apply for a medical service, they are still reluctant and are not convinced much in the efficiency of these 
services. This behavior has already become a characteristic feature of the nation.

Armenia wants to become a part of Europe but it is an Asian country and its population is hypersensitive (in contrast, e.g. to Americans who are cold-minded and pragmatic, sometimes romantic-pragmatic). So, as have answered the majority of the students: "telling the truth to the patient is only justified in economically developed countries."

At the end of the lecture the students were again handed forms sent by UNESCO containing 20 questions, in four thematic blocks. In contrast to PhD students, the freshmen, who had only studied this subject for 26 hours (4 hours with 2 testing) and didn't know anything about it before, gave relatively poor answers (Davtyan, 2012, pp. 505-507).

The doctor must have a high sense of responsibility towards the patient and a high degree of tolerance. If in doctor-patient relationship there is no tolerance, patients cannot trust the doctor. Agreement between doctor and patient largely depends on the existence of a trust atmosphere. Trust is one of the characteristic features of public relations and is manifested both in the personal and social levels. It is a social virtue. The harmony of human and social relation is directly determined by the degree of trust in the society. That is why it is obvious that in the modern world trust, tolerance are the main regulative principles.

\section{REFERENCES}

Avinash, S. (2015). Global Bioethics Enquiry. Informed Consent and Geriatric Psychiatry: a clinical and research viewpoint. The scholarly publication of the UNESCO chair of Bioethics.

Chieffi, L. (2013). Bioethical Issues by the Interuniversity Center for Bioethics Research (C. I. R. B.). Areas of constitutional protection and development of interpretation of the government of his own body. Napoli.

Davtyan, S.H. (2013). Bioethics. Yerevan.

Davtyan, S.H. (2012). Experimental Course of Bioethics upon the Bioethics Core Curriculum of UNESCO: Methodology and Results of Investigation Medicine and Law. Number 4.

Lektorskiy, V.A. (1997). O tolerantnosti, plyuralizme $i$ krititsizme (About Tolerance, Pluralism and Criticism, in Russian), Voprosy filosofii, No 11.

Sedova, N.N., \& Basov, A.V. (2015). Eticheskie parametry personalizirovannoi meditsiny (Ethical Parameters of Personalized Medicine, in Russian), Federalnii nauchno-prakticheskii zhurnal, Volgograd, Izdatel'stvo VolgGMU, No2 (16). 